\title{
Objetos de Aprendizagem de Matemática para o ensino médio e educação profissional técnica
}

The Learning Objects of Mathematics for middle school and professional education technique

\author{
Dimas Felipe de Miranda ${ }^{1}$ \\ João Bosco Laudares ${ }^{2}$ \\ Lana Paula Ricotta Nery ${ }^{3}$ \\ Tânia Fernandes Bogutchi ${ }^{4}$ \\ Yara Patrícia Barral de Queiroz Guimarães ${ }^{5}$
}

\section{Resumo}

Este artigo apresenta resultados de pesquisa em informática educativa com a criação de Objetos de Aprendizagem - OA de Matemática para o ensino médio e técnico profissional. Foi desenvolvido um projeto de investigação, financiado por um órgão de fomento, em trabalho cooperativo com os pesquisadores de um Mestrado Profissional em ensino de Ciências e Matemática e professores do ensino técnico de várias instituições federais de educação. Os OA são constituídos por atividades relativas aos conteúdos do ensino médio e aplicações na área técnica em eletricidade, química, mecânica, entre outras. Foram utilizados softwares da geometria dinâmica, principalmente o GeoGebra, e aplicativos computacionais que permitem dar movimento às figuras e gráficos de modo a contribuir com uma melhor visualização. Os $O A$ são produtos educacionais que estão nas dissertações dos mestres envolvidos nas pesquisas e armazenados num repositório, com acesso livre.

\footnotetext{
${ }^{1}$ Doutor em Geografia - Tratamento da Informação Espacial: PUC Minas, Professor da graduação e do Mestrado em Ensino de Ciências e Matemática da PUC Minas, dimasfm48@yahoo.com.br.

${ }^{2}$ Doutor em Educação: PUC SP, Professor da Graduação e do Mestrado em Ensino de Ciências e Matemática da PUC Minas, jblaudares@terra.com.br.

${ }^{3}$ Mestre em Ensino de Ciências e Matemática: PUC Minas, Professora na Fundação de Educação para o trabalho de Minas Gerais/Utramig, lanaricotta@hotmail.com.

${ }^{4}$ Doutora em Geografia - Tratamento da Informação Espacial: PUC Minas, Professora da Graduação e do Mestrado em Ensino de Ciências e Matemática da PUC Minas, bogutchi@pucminas.br.

${ }^{5}$ Mestre em Ensino de Ciências e Matemática: PUC Minas, Professora do Centro Federal de Educação Tecnológica de Minas Gerais - CEFET/MG, yara.matematica@cefetmg.br.
} 
Palavras-chave: Educação profissional. Ensino Médio. Ensino de matemática. Objetos de aprendizagem.

\section{Abstract}

This article presents results of a research based in resources of computer programs with the creation of Learning Objects from Mathematics for secondary school and technical professional education. Developed a research project, financed by a sponsor institution, in cooperative work with researchers from Professional Master in Science Teaching and Mathematics Education and teachers of technical education of the several federal educational institutions. The Learning Objects have activities with contents of the secondary school and applications in technical areas of electricity, chemistry, mechanic among others. Were used dynamic geometry software, mainly the GeoGebra, and computational applications programs that give movement to the figures and graphs in order to contribute to a better view. The Learning Objects are educational products that are in the dissertations of the professors involved in research and stored in a repository, with free access.

Keywords: Secondary School. Professional Education. Teaching of Mathematics. Learning Objects.

\section{Introdução}

Este artigo apresenta resultados de uma pesquisa financiada por um órgão de fomento, cujo objetivo foi criar material didático para o ensino médio e técnico, no âmbito de um mestrado profissional em ensino de ciências e matemática, oferecido por uma instituição privada.

É resultado de um trabalho cooperativo de dois grupos de estudo e pesquisa, sendo um vinculado ao mestrado referido e o outro, de uma instituição federal de ensino.

Todos os OA tiveram a participação de mestres egressos do mesmo mestrado e que são docentes da educação básica em instituições públicas da educação profissional. Também contemplam atividades do conteúdo do ensino médio de matemática e trazem aplicações de cursos técnicos, especialmente das áreas de eletricidade, eletrônica, mecânica e química, como por exemplo: as atividades sobre circuitos na área de eletricidade, a visualização de vistas de uma peça estudada em desenho técnico na área de mecânica, dentre outras. 
Outro produto resultante do projeto foi a criação de um Repositório Virtual para armazenar os OA com possibilidade de fácil acesso aos estudantes e professores. Desta maneira, os docentes do ensino médio e técnico poderão fazer uso dos $\mathrm{OA}$ em suas aulas e, os estudantes, terão oportunidade de apoiar seus estudos com este material didático. O repositório que armazena os OA com possibilidade de acesso e uso é denominado "Repositório de Objetos de Aprendizagem de Matemática para o Ensino Médio e Profissional" - ROAMEP.

O referencial teórico que deu sustentação aos estudos e as investigações se pautou na temática informática educativa, quanto na geração de objetos virtuais de aprendizagem, com a finalidade de melhoria da compreensão dos conceitos matemáticos por meio do uso da habilidade de visualização, como mostra Borba (2007). Na criação das atividades, a sequência didática, como padrão metodológico, propiciou referência para o desenvolvimento de passos ou etapas na elaboração de questões para ensejar análise, investigação com conjecturas e reflexões necessárias à assimilação dos conceitos e estruturas dos conteúdos em estudo, conforme Zabala (1998).

A educação matemática tem contemplado nas suas temáticas atuais os recursos das mídias virtuais, bem como a produção de material concreto e aplicativos informatizados, que favorecem a diversificação metodológica com múltiplas representações. A multiplicidade de estratégias didáticas proporciona eficácia da aprendizagem.

Zullato (2002) pesquisou o perfil dos docentes que usam softwares de geometria dinâmica destacando as perspectivas e potencialidades relacionadas ao seu uso, não se limitando apenas em substituir o lápis e papel pelo computador, mas procurando a eficiência das práticas desenvolvidas com compreensão e a aprendizagem significativa com uma postura mais ativa do professor e estudante.

Ao produzir materiais, visando o ensino técnico, busca-se contribuir para uma extensa rede de instituições federais, que são escolas, centros, institutos e universidade tecnológica que oferecem educação técnica de qualidade reconhecida pela comunidade acadêmica e diversos setores sociais, 
especialmente, as empresas que recebem os egressos dessas instituições. Com educação integral, formação geral e para o trabalho, os docentes destas instituições podem, pela sua capacidade profissional e pelas condições de trabalho, diferenciadas de outras instituições públicas e privadas de ensino, serem paradigmas de uma educação com qualidade e eficaz em seus objetivos de formação profissional e da cidadania.

A proposta objetiva também a interdisciplinaridade da matemática com disciplinas técnicas fomentando o diálogo com docentes de várias áreas.

\section{A educação técnica no Brasil - seu projeto pedagógico e estruturação curricular}

A Educação Técnica tem sua origem, no início do século passado, com a criação de uma rede de instituições da educação básica e técnica, cujo objetivo foi atender uma demanda de formação de profissionais para o mercado de trabalho, com a industrialização do país e o desenvolvimento da economia brasileira.

A Educação Tecnológica também foi contemplada, ampliando cursos superiores de graduação com expansão de universidades e institutos; estes últimos com projeto pedagógico favorecendo uma formação verticalizada do técnico, tecnólogo, bacharéis e licenciados. A qualificação destas instituições permite a oferta também da pós-graduação lato-sensu e stricto-sensu. Assim, há numa mesma instituição, a possibilidade da oferta da educação básica à pós-graduação.

O ensino médio brasileiro, que é a última etapa da educação básica, há anos tem passado por constantes reformas com vistas à melhoria da qualidade e sua consolidação. A Reforma de 2016 busca, mais uma vez, traçar percursos diferenciados com base comum; a respeito do ensino da Matemática, a definição de conteúdos a preserva como disciplina básica e obrigatória, ratificando a interdisciplinaridade com as demais disciplinas de cultura geral e profissional.

A educação profissional técnica assim definida, no nível do ensino médio, anteriormente em currículo integrado (numa mesma estrutura curricular com dois núcleos - ensino médio e técnico profissional) passou por reformas com a 
separação dos dois núcleos, via Decreto 2208/1997. Entretanto, com o movimento político das instituições de educação profissional novo decreto foi editado, o 5154/2004, o qual regulamenta a articulação do ensino técnico e médio, e traz novamente a possibilidade de integração dos dois núcleos num mesmo Projeto Pedagógico. Assim, ficam definidos dois tipos de educação profissional no Brasil:

1. Educação Profissional Técnica, de nível médio de escolaridade;

2. Educação Profissional Tecnológica, de nível superior.

O espaço para o cidadão desenvolver habilidades que lhe permitam efetivar suas relações sociais envolve a educação básica. É neste espaço que o indivíduo interage, assimilando valores, procedimentos, costumes e quando a cultura geral é exposta a ele. Saberes de Matemática, História, Biologia, da linguagem oral e escrita estão presentes nos currículos da educação básica, ensino fundamental e médio. Por outro lado, segundo KUENZER (2002), a educação é uma práxis cultural a exigir do homem habilidades para ser cidadão político e produtivo, como agente interventor do processo social.

Em 2010, a Rede de Educação Profissional Técnica e Tecnológica completou seu centenário, pois foi criada no início do século XX. Já na entrada do século XXI, o Brasil, como país emergente economicamente, no interior da globalização, vem exigindo profissionais com crescente qualificação, formação básica e profissional para responder a competitividade no cenário internacional.

A formação e atuação docente, neste cenário, demandam uma qualificação profissional para inovações metodológicas, criação de estratégias para uma educação progressista e preparação de materiais didáticos como apoio às atividades para o ensino e aprendizagem.

\section{3 ensino de matemática - Informática educativa e objetos de aprendizagem}

O processo de ensino e aprendizagem de matemática tem sido objeto de um grande número de pesquisas. A diversidade dos métodos didáticos está contemplada, sempre com a busca por ensinar com compreensão, ao se ter 
estratégias com variedade de recursos. Deste modo, o trabalho com os conceitos pode facilitar o entendimento de propriedades, de proposições e teorias que não se restringem a habilidade procedimental de cálculos e uso de algoritmos.

A visualização gráfica proporciona o desenvolvimento de interpretação e análise, fonte para uma aprendizagem eficaz. Transformar o ambiente de ensino com a busca de movimento e dinamismo traz o estudante para o centro do processo escolar, transformando a ação centrada no professor, que passa a ter oportunidade de variar suas estratégias didáticas e trabalhar colaborativamente com o estudante. As representações para um mesmo objeto, segundo Duval (2009) podem favorecer o entendimento do estudante. Os gráficos e diagramas na geometria, as tabelas numéricas e estatísticas na aritmética, as equações com suas variáveis e coeficientes na álgebra, o falar matemática na redação oral e escrita constituem tipos de representações semióticas. Duval (2009) considera que a compreensão de um saber pelo estudante se consolida ao fazer pelo menos duas representações do mesmo objeto de estudo.

A formação inicial e continuada do professor de matemática se faz com efetividade ao potencializar, então, uma inserção de variadas ações didáticas no seu planejamento e prática educativa. Para isto, a crescente produção de materiais voltados para a utilização das TIC (computador, applets, internet e aplicativos virtuais ou não virtuais) pode ser um suporte para a edificação de um ambiente de trabalho e não só de uma aula assistida.

Entretanto, a intervenção do professor no projeto e aplicação de tecnologias variadas com diferentes mídias, não se faz de maneira fácil e é importante identificar questões relacionadas às dificuldades de preparação e implementação de múltiplos recursos metodológicos (Miskulin, 2003; Borba e Penteado, 2007; Ponte, Oliveira, Varandas, 2003).

A produção de materiais para a implementação de uma didática progressista, com uma aula dinâmica e atraente, recentemente tem contemplado a criação e uso do Objeto de Aprendizagem - OA. Este pode ser entendido como entidades digitais que estão disponíveis na internet, possibilitando uma nova forma de ensino que 
permite 0 acesso simultâneo em diferentes lugares e plataformas (WILEY, 2000). O mesmo autor destaca que os $O A$ se fundamentam no paradigma de orientação ao objeto da ciência da computação, integrado ao projeto pedagógico.

A concepção dos OA criados para o ensino médio e educação profissional, apresentados neste artigo, tem embasamento em Wiley (2000). Foram estruturados com atividades a serem desenvolvidas com uso das ferramentas da informática, especificamente, na geração de estratégias integradas ao processo de ensino. A construção dos OA favorece a integração dos docentes dos dois núcleos, ensino de matemática e de disciplinas técnicas, ao desenvolverem um currículo integrado numa mesma instituição e numa mesma plataforma curricular. A convivência se faz naturalmente nos debates acadêmicos, nos projetos de extensão e de investigação, nas ações do Projeto Pedagógico institucional.

Para cumprir esta meta de integração institucional, foi realizado um levantamento dos conteúdos matemáticos mais trabalhados no contexto da educação profissional para dar diretrizes à programação e criação dos $\mathrm{OA}$, a partir dos parâmetros do Projeto Pedagógico institucional e da decisão política dos docentes, quanto à didática e métodos de ensino e aprendizagem definidos. Deste modo, há que se edificar uma sequência de conteúdos e uma sequência didática, o que ocorreu nos OA segundo diretrizes de Zabala (1998).

Inicialmente, identificou-se a sequência dos conteúdos, com seus conceitos, propriedades, cálculos, proposições do currículo do ensino médio que deveriam ser explorados já visando as aplicações na área técnica profissional, as quais foram investigadas para serem contempladas. Desta forma, foram levantadas questões de conhecimentos do ensino médio e do ensino técnico profissional.

Em seguida, consoante com a estruturação de $\mathrm{OA}$, foi construída uma sequência didática, definindo-se parâmetros conceituais e operacionais metodológicos. A partir daí, foi realizada uma pesquisa sobre aplicativos, softwares e outras mídias para criação do design, o que é próprio da estrutura de todo objeto de aprendizagem. Videos também foram utilizados. Definidas as duas sequências, 
de conteúdo e didática, foram elaboradas atividades, como é característico em toda concepção e estruturação de um OA.

Uma das características de um objeto de aprendizagem é sua usabilidade com reutilização e possibilidades de intervenções para ampliações e reestruturações, o que pode ocorrer com os OA criados, que estão abertos para remodelações e inserções seja de conteúdo, aplicações ou outras inovações didáticas.

\section{Composição dos objetos de aprendizagem criados}

Os conteúdos da programação de matemática levantados se transformaram em objeto de estudo e investigação dos criadores dos objetos, professores da educação básica e mestres em ensino de matemática. Desta forma, foram construídos 8 (oito) objetos (dentre outros) que são citados a seguir, com apoio de mídias da informática educativa, especialmente softwares de geometria dinâmica, aplicativos, applets, dentre outros recursos informatizados.

Cada OA foi constituído por atividades explorando conceitos, definições, propriedades, aplicações do conteúdo específico da teoria da matemática, em forma de representações gráficas e de diagramas, com questões que o estudante deve resolver com análise e relacionando seus conhecimentos prévios adquiridos anteriormente ao uso do OA. É importante sempre destacar que o objeto de aprendizagem é um instrumento de apoio às aulas expositivas, e nunca a substituição dessas.

Uma segunda parte do $\mathrm{OA}$ se refere às aplicações do conteúdo da matemática necessária aos cursos da educação profissional técnica em várias áreas: eletricidade, mecânica, química, entre outras. Assim, o estudante deve relacionar seus conhecimentos da área técnica ou tecnológica com os da matemática.

A próxima etapa compreendeu uma pesquisa dos recursos de informática que deveriam dar subsídios à idealização do design da estrutura para desenvolvimento das telas, dos diagramas, dos gráficos com a utilização de 
variados aplicativos da informática e de vídeos para a ilustrações dos fenômenos investigados. Uma dificuldade foi quanto a definição dos recortes para garantir uma essência dos saberes em processo de estudo, em conseqüência da dimensão dos OA. Todas as atividades dos OA são dinâmicas, com movimentação das figuras, diagramas e gráficos, o que foi favorecida pelos softwares e aplicativos utilizados.

Os OA desenvolvidos foram aplicados a estudantes de cursos técnicos de várias instituições, em sua maioria escolas federais, sendo que, em geral, o idealizador e desenvolvedor atuava como docente. Os resultados das resoluções dos alunos foram analisados e registrados nas respectivas dissertações, como produto do mestrado, como já mencionado anteriormente.

O Quadro 1 mostra alguns dos OA desenvolvidos.

\begin{tabular}{|c|c|}
\hline Título & Descrição \\
\hline $\begin{array}{l}\text { Estudo de modelos de fenômenos } \\
\text { representados por funções. }\end{array}$ & $\begin{array}{l}\text { Esse OA trata do conceito de função, que } \\
\text { representa um modelo matemático, e } \\
\text { vários estilos de aprendizagem são } \\
\text { privilegiados. Software utilizado: GeoGebra. }\end{array}$ \\
\hline $\begin{array}{l}\text { Objeto de Aprendizagem para funções } \\
\text { exponencial e logarítmica com aplicações } \\
\text { no ensino médio e em cursos técnicos. }\end{array}$ & $\begin{array}{l}\text { O objetivo principal deste OA é a } \\
\text { interpretação geométrico-gráfica das } \\
\text { funções exponencial e a logarítmica. } \\
\text { Software utilizado: GeoGebra. }\end{array}$ \\
\hline $\begin{array}{l}\text { Geometria plana e sólida para o ensino } \\
\text { médio e técnico profissionalizante de } \\
\text { Mecânica. }\end{array}$ & $\begin{array}{l}\text { Por meio do software GeoGebra e um editor } \\
\text { de código aberto ExerLearning, foi criada } \\
\text { uma sequência de atividades em três eixos: } \\
\text { geometria plana, geometria sólida e } \\
\text { aplicações técnicas na área de mecânica. }\end{array}$ \\
\hline $\begin{array}{l}\text { Utilização de Resolução de Problemas em } \\
\text { Fenômenos Físicos da área Eletrotécnica. }\end{array}$ & $\begin{array}{l}\text { Este OA utilizou a metodologia da resolução } \\
\text { de problemas como recurso tecnológico e } \\
\text { didático para o ensino de Sistemas de } \\
\text { Equações Lineares. Software utilizado: } \\
\text { GeoGebra. }\end{array}$ \\
\hline
\end{tabular}




\begin{tabular}{|c|c|}
\hline $\begin{array}{c}\text { Sistema de equações lineares aplicadas em } \\
\text { circuitos. }\end{array}$ & \\
\hline $\begin{array}{c}\text { Estudando medidas estatísticas num curso } \\
\text { de turismo: literacia, raciocínio e } \\
\text { pensamento estatístico. }\end{array}$ & $\begin{array}{l}\text { Este OA apresenta uma sequencia de } \\
\text { atividades sobre a Estatística. Seu objetivo é } \\
\text { desenvolver nos alunos a literacia } \\
\text { estatística, além do raciocínio e o } \\
\text { pensamento estatístico. }\end{array}$ \\
\hline $\begin{array}{l}\text { Funções arco seno e arco cosseno } \\
\text { aplicadas na área eletrotécnica. } \\
\text { Explorando a trigonometria do modelo } \\
\text { harmônico simples: uma aplicação no } \\
\text { estudo dos sinais. }\end{array}$ & $\begin{array}{l}\text { A proposta desse OA é contribuir para a } \\
\text { compreensão das funções seno e cosseno } \\
\text { bem como suas inversas, pela interpretação } \\
\text { geométrico-gráfica. }\end{array}$ \\
\hline $\begin{array}{l}\text { Álgebra Booleana e Modelos Matemáticos } \\
\text { de simplificação em cursos técnicos. }\end{array}$ & $\begin{array}{l}\text { Este OA apresenta a álgebra booleana - } \\
\text { base da aritmética computacional - visando } \\
\text { a aprendizagem e fixação das funções } \\
\text { booleanas, aplicação de teoremas, } \\
\text { propriedades e identidades matemáticas } \\
\text { para a simplificação de expressões. }\end{array}$ \\
\hline
\end{tabular}

Quadro 1: descrição dos OA que compuseram o projeto.

Foram selecionados dois OA para serem apresentados neste artigo, cuja opção foi pelos temas Funções e Geometria.

\section{Objeto de aprendizagem sobre função - estudo de modelos de fenômenos representados por funções.}

Função é um conceito básico para todo o desenvolvimento da matemática, e tem aplicações nas diversas áreas do conhecimento, como na matematização dos fenômenos naturais, sociais, tecnológicos e econômicos.

A base para várias disciplinas técnicas é a compreensão de conceitos matemáticos envolvidos no estudo de modelos matemáticos. Isto é, um modelo pode ter representações gráfica, numérica, de equação ou de uma função. A boa compreensão do estudo de funções é imprescindível para o trabalho com a 
modelagem matemática e construção de modelos matemáticos que estão presentes nas áreas da Ciência e Tecnologia.

Segundo Biembengut (2003, p.12) um modelo matemático é diferente de modelagem matemática, uma vez que um modelo é "um conjunto de símbolos e relações matemáticas que procura traduzir, de alguma forma, um fenômeno em questão ou problema de situação real" e modelagem matemática é "o processo que envolve a obtenção de um modelo".

Para a construção dos modelos matemáticos apresentados nesse OA, as funções foram analisadas sob quatro parâmetros, que Stewart (2003) chamou de "regra dos quatro passos": verbal, numérico, visual e algébrico. Para as construções gráficas, foi utilizado o GeoGebra e para a montagem das atividades a opção foi pelo editor livre ExeLearning.

Inicialmente, as atividades do OA são relativas a definição de função, estudo do domínio, do conjunto-imagem, do seu estudo gráfico e de propriedades do seu comportamento (crescimento/decrescimento, máximos e mínimos) e de alguns tipos de função, como linear, quadrática, recíproca, entre outras. São mostradas, aqui, quatro atividades dentre as que compõem este $O A$.

A primeira envolve o estudo e análise da função par e função ímpar. $O$ objetivo da atividade é, além de identificar estes tipos de função, promover o entendimento desse conceito por meio da representação gráfica. Dinamicamente, por meio de uma sequência de perguntas e orientações, o aluno constrói os gráficos das funções e elabora conjecturas a respeito de suas diferenças; chegam assim às conclusões sobre as principais diferenças entre uma função par e uma ímpar. 


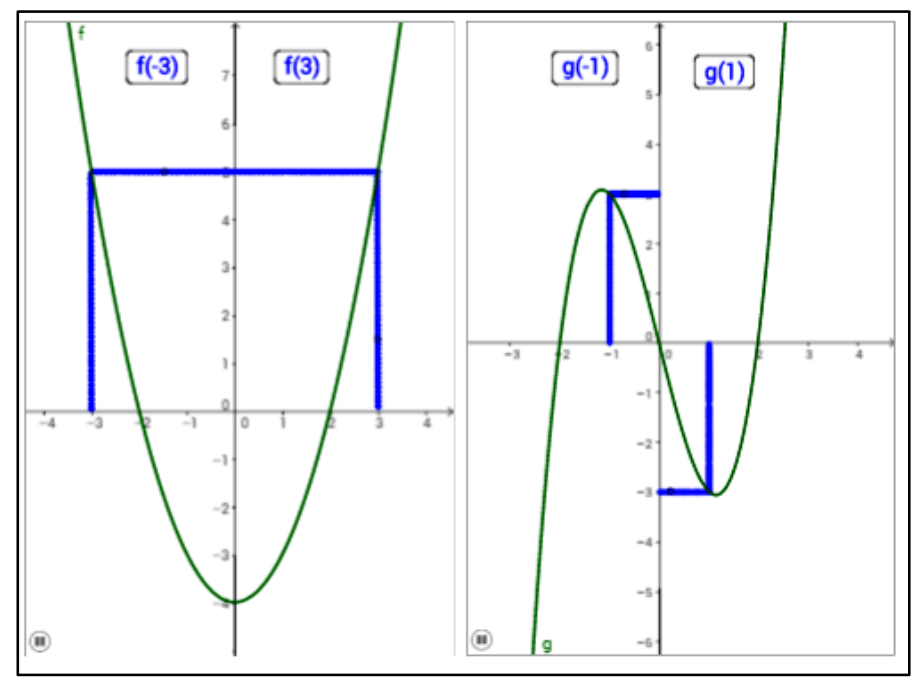

Figura 1: representação gráfica da função par e ímpar.

Fonte: elaborado pelo autor do OA

A segunda atividade aqui apresentada objetiva a análise e compreensão da função recíproca, interagindo a representação gráfica com a algébrica. A figura 2 ilustra a investigação ao qual o estudante é convidado a realizar, observando as imagens que a função assume a partir de parâmetros estabelecidos.

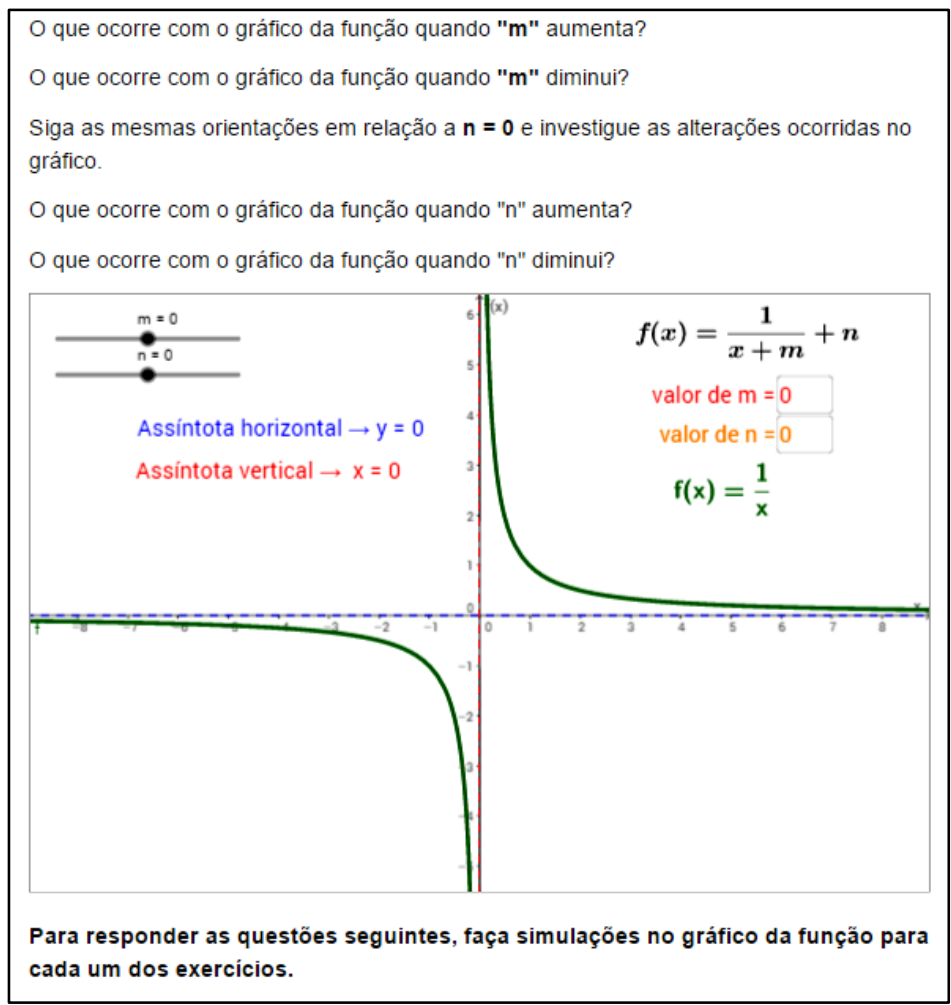

Figura 2: representação gráfica da função recíproca Fonte: elaborado pelo autor do OA. 
Pode ser observado que a escolha da função $y=\frac{1}{x+m}+n$ permite a realização de muitas experimentações, possibilitando um momento rico de investigação matemática. O uso do comando "controle deslizante" do GeoGebra contribui para a observação de uma grande quantidade de valores dos parâmetros $m$ e $n$, e as alterações ocorridas no gráfico da função.

A terceira atividade é relativa à aplicação de um fenômeno de vibração de molas para analisar um modelo. A figura 3 ilustra uma interessante aplicação do conceito das funções lineares e funções quadráticas, e suas representações na vibração de molas:

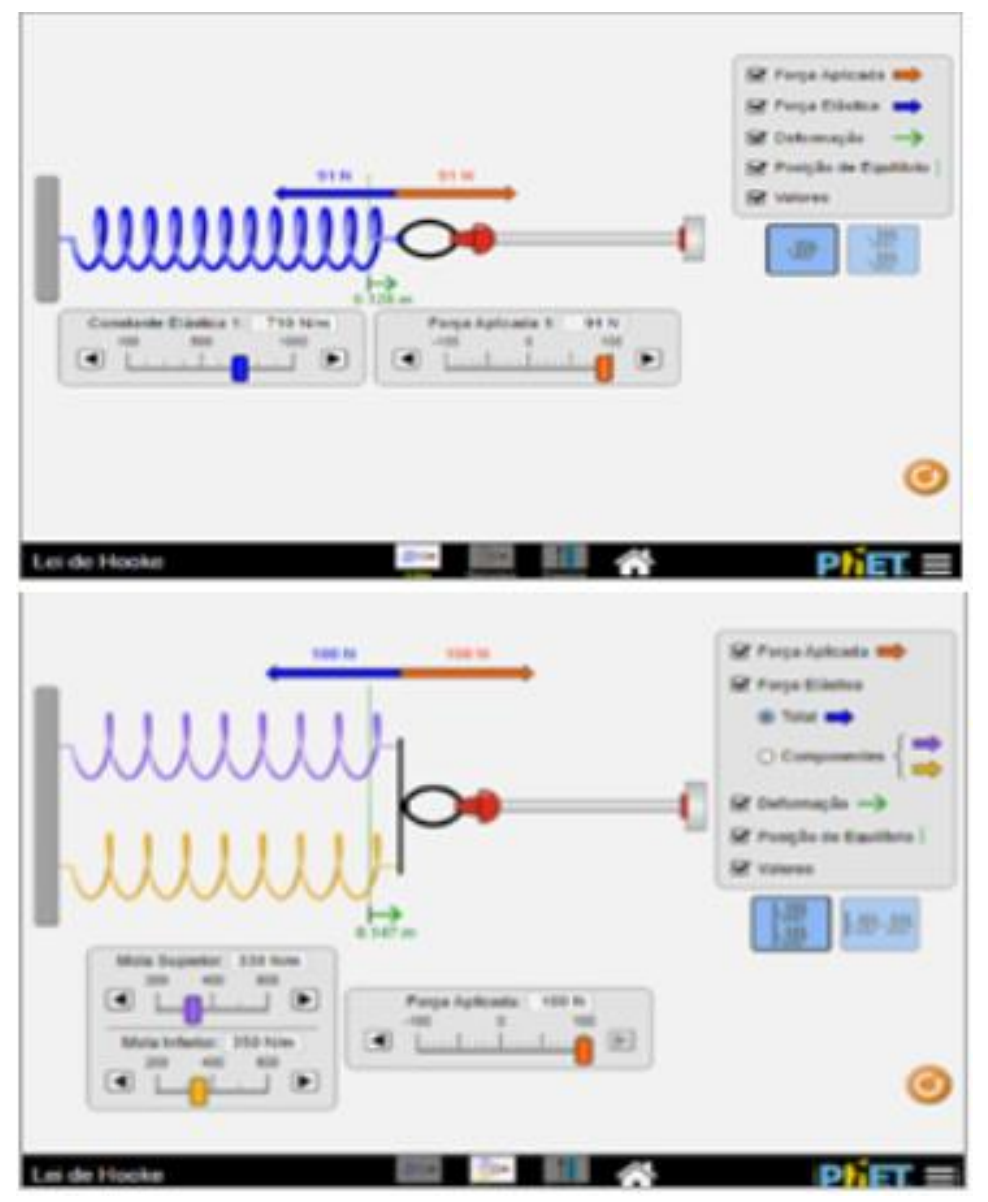

Figura 3: diagrama da representação da Lei de Hooke Fonte: https://phet.colorado.edu

Conforme ilustra a figura 3, um simulador do site https://phet.colorado.edu foi utilizado, quando o aluno é convidado a investigar o que ocorre com a variação 
da força aplicada e a constante elástica em uma ou duas molas horizontais (modelo linear). Algumas questões sobre a lei de Hooke foram apresentadas e, no final, foi estudada a energia potencial elástica, com simulações gráficas que representam o fenômeno (modelo quadrático) no próprio simulador.

A quarta atividade se mostra bastante atraente para o público do ensino médio, por se tratar do estudo de uma pista de skate, conforme pode ser observado na figura 4.

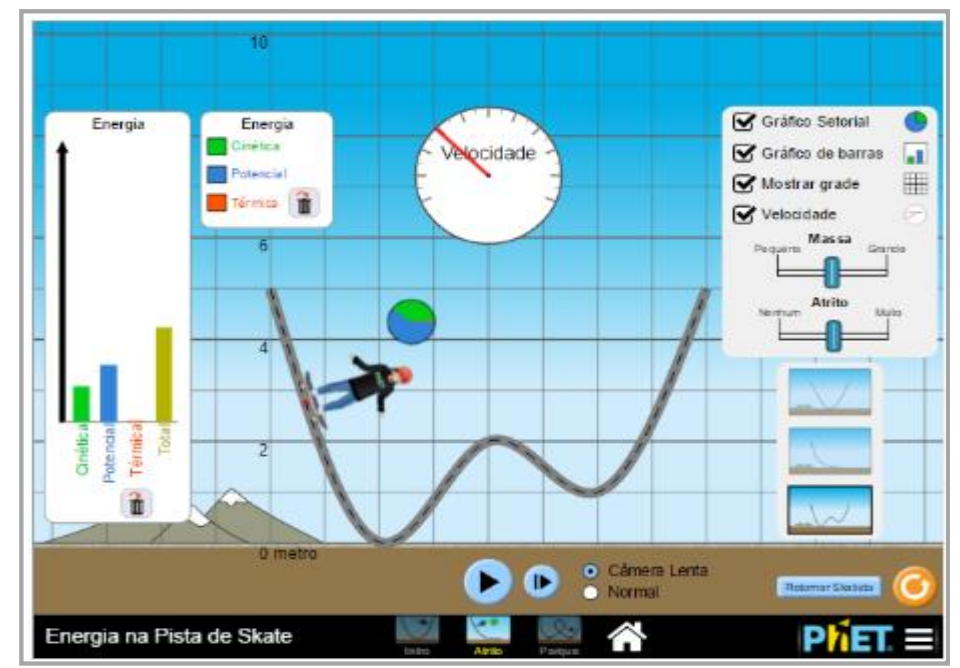

Figura 4: parque de skate - diagrama de um modelo polinomial. Fonte: elaborado pelo autor do OA.

O objetivo desta atividade é aplicar os modelos quadráticos, recíproco e polinomial, por meio do simulador do site https://phet.colorado.edu, além da contextualização de funções com várias áreas do conhecimento.

Permite também a resolução de problemas de fenômenos físicos, uma vez que o simulador também mostra o valor da energia cinética, potencial e térmica em todos os pontos das rampas e também a velocidade atingida pelo skatista. 


\section{Objeto de aprendizagem sobre geometria plana e sólida para o ensino médio e técnico profissionalizante de mecânica}

O OA apresentado tem aplicações na área de Mecânica, por envolver um conteúdo de grande aplicação no desenho técnico de peças. A representação geométrica é realizada com grande ênfase, mas o tratamento algébrico também é explorado.

Foi desenvolvida uma sequência didática dividida em três eixos: geometria plana, geometria sólida e aplicações na área de mecânica. Como principal referencial teórico, tem-se o Modelo de Van Hiele, que considera o processo de desenvolvimento do pensamento geométrico como uma sequência de cinco níveis: reconhecimento, análise, abstração, dedução e rigor, e não passar por uma dessas etapas pode implicar no insucesso das seguintes.

Inicialmente, este OA contribui para o aprendizado e compreensão sobre a área das figuras planas, a partir da área do retângulo, uma vez que relaciona todas as figuras planas com o retângulo. A figura 5 exemplifica essa noção, mostrando como a área do trapézio pode ser visualizada pela área do retângulo.

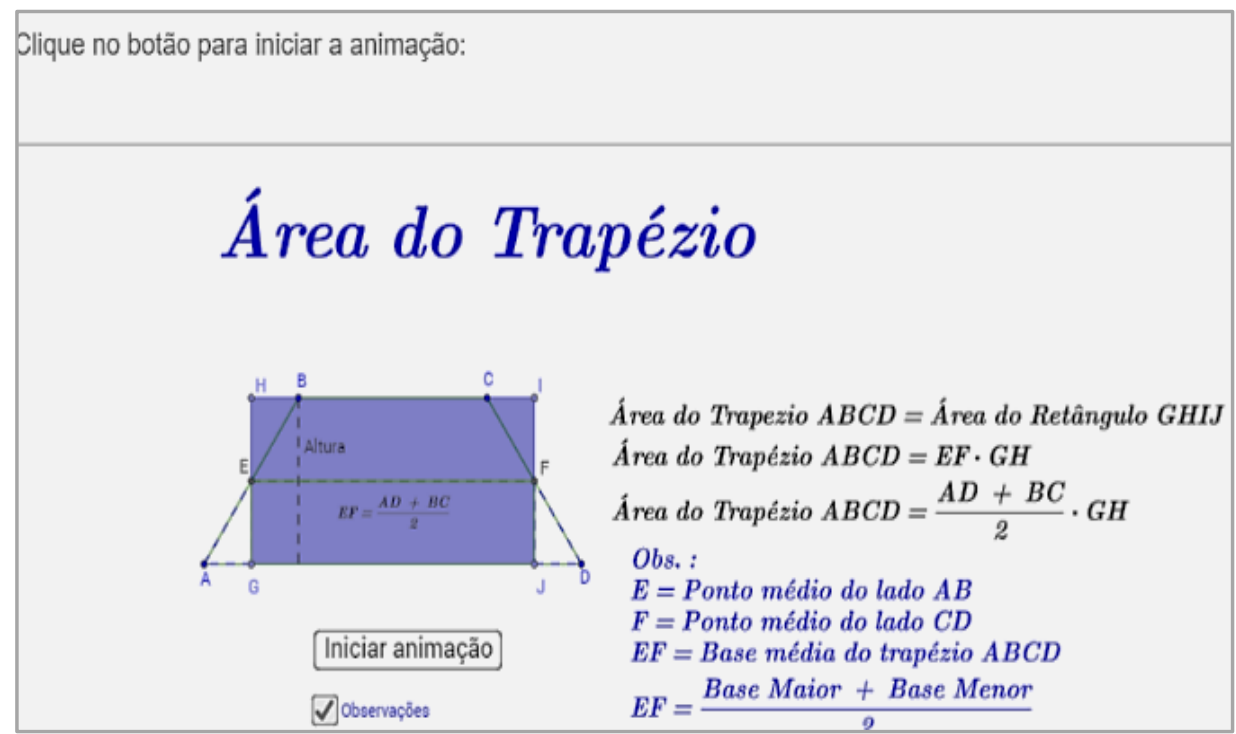

Figura 5: interpretação da área do Trapézio Fonte: Elaborado pelo autor do OA. 
A experiência com o círculo e a circunferência se mostra também interessante, pois leva o estudante a perceber a diferença entre um e outro. Em seguida, por meio de partições realizadas no círculo, com a possibilidade de aumentar a quantidade de setores circulares obtidos, o estudante consegue encaixar esses setores, formando um quadrilátero.

Assim, o estudante observa que, quanto maior for o número de partições realizadas, mais o quadrilátero se aproximará de um retângulo de base $\pi \mathrm{r}$ e altura r. A figura 6 ilustra a experiência realizada.

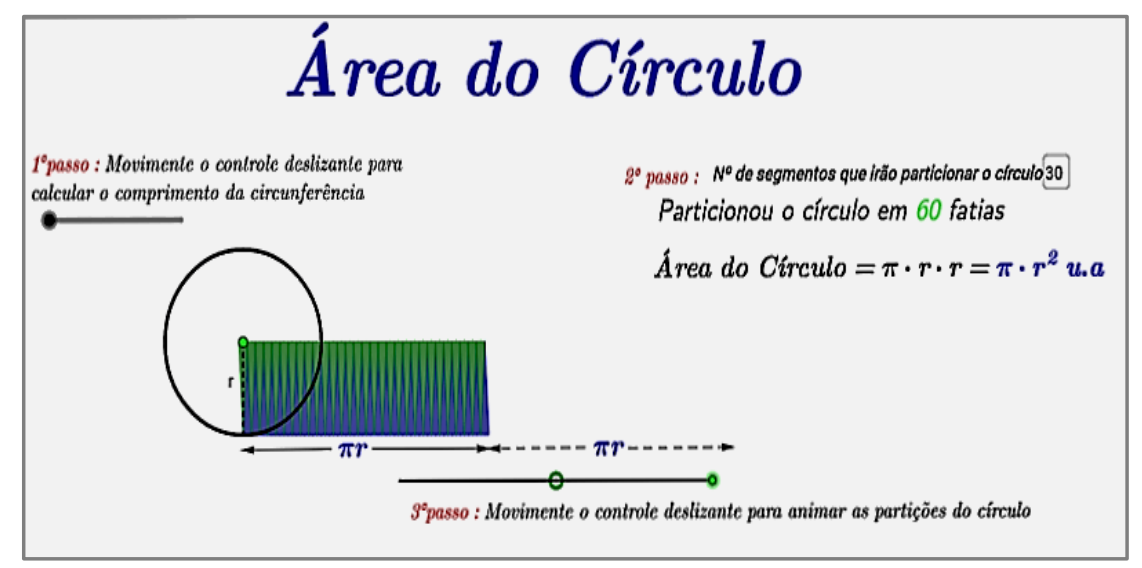

Figura 6: interpretação geométrica da área do círculo.

Fonte: elaborado pelo autor do OA.

Na sequência, o cálculo da área e do volume das figuras espaciais também ocorre de forma investigativa, pois as atividades levam o aluno a observar a planificação dos sólidos, bem como suas propriedades, seções e elementos, para então construir expressões que permitam o cálculo da área e do volume. 


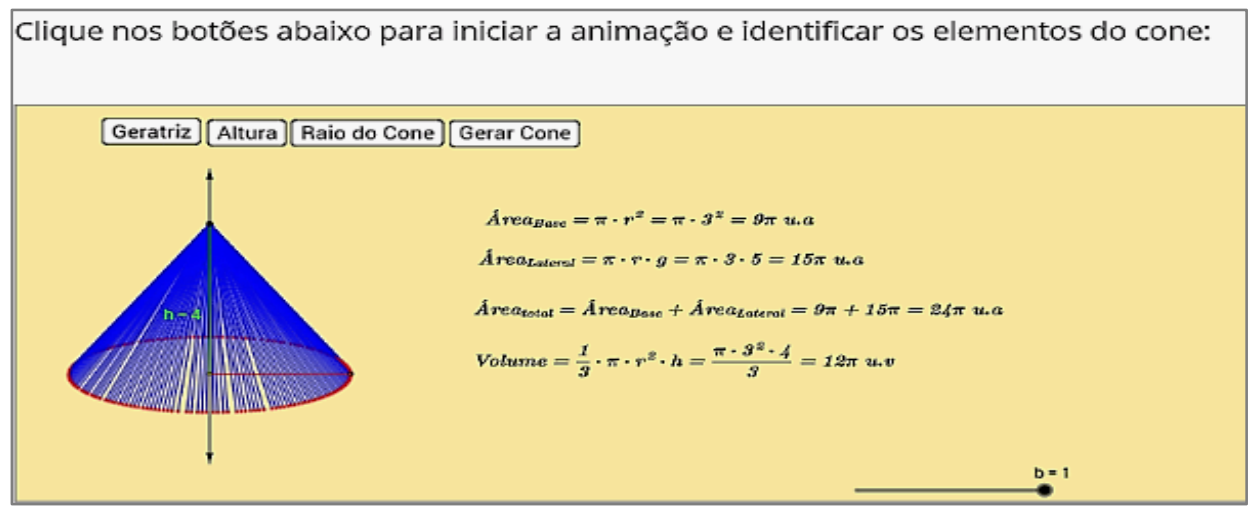

Figura 7: interpretação geométrica do Tronco de Cone Fonte: Elaborado pelo autor do OA.

Por meio da experimentação, o aluno pode escolher o número de arestas que seu sólido geométrico terá, definindo assim o tipo de sólido. Quanto aos sólidos de revolução, o aluno poderá investigar cada figura, aproveitando a grande vantagem que um software dinâmico apresenta: a possibilidade de movimentar o sólido, observando-o sob diferentes vistas frontais e laterais.

Após criar atividades e questões com a determinação da área e volumes de superfícies, com a possibilidade de fazer todo o estudo com representação geométrica, as próximas atividades exploram aplicações da área técnica profissional de mecânica do desenho técnico.

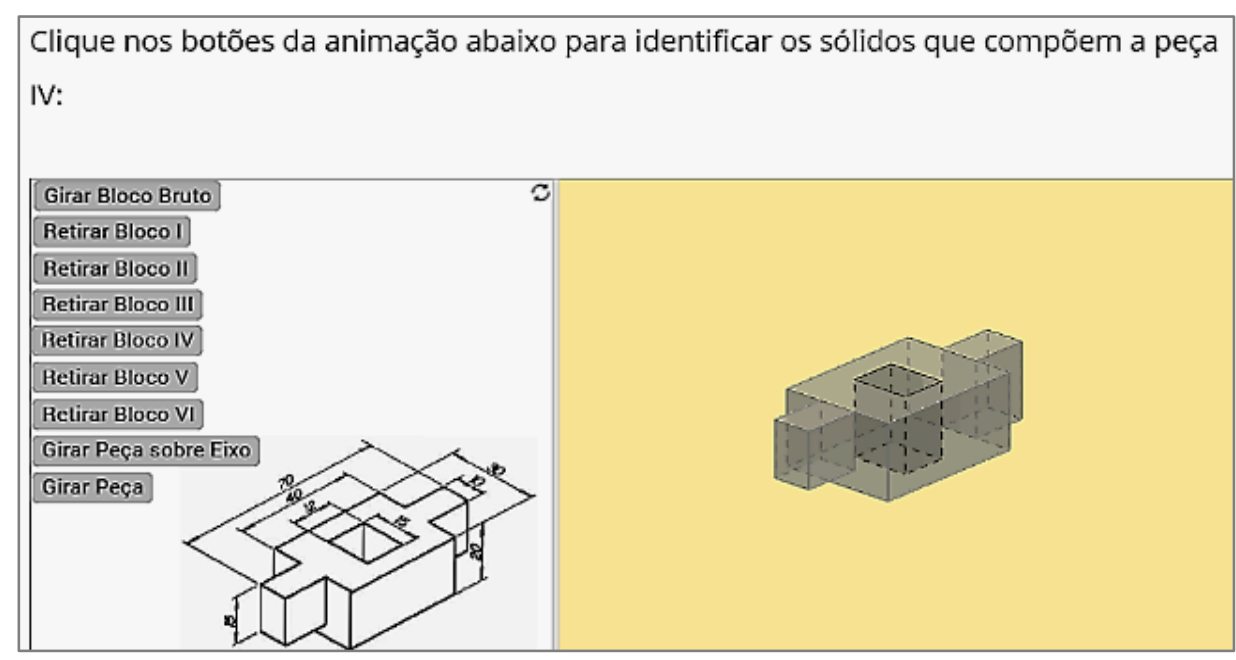

Figura 8: Estudo das vistas de uma peça

Fonte: Elaborado pelo autor do OA 
A figura 8 mostra o desenho de uma peça, em que é possível perceber as figuras planas bem destacadas, formando uma figura sólida, e real como se pode verificar.

O software GeoGebra é utilizado como suporte, além de um editor de conteúdos didáticos em suporte digital, de código aberto, o ExerLearning.

\section{Considerações finais}

A criação dos objetos de aprendizagem para o ensino médio e educação técnica profissional cumpre dois objetivos: o primeiro de desenvolver a habilidade de visualização para apropriação dos conceitos trabalhados no ensino médio e, o segundo, de utilizá-los nas aplicações dos conteúdos dos cursos técnicos profissionais, nesse mesmo nível de ensino.

Parte-se da diversificação metodológica, como facilitadora da compreensão conceitual das proposições de matemática, em equilíbrio com o método procedimental, este relativo aos cálculos operacionais e uso de algoritmos. Consoante a Duval (2009), que assegura a probabilidade de obtenção do conhecimento, se este for tratado por um mínimo de duas representações, utilizouse das TICs, como facilitadora para múltiplas representações: a representação de gráficos e diagramas, a variação das equações com alteração de seus parâmetros, e as aplicações com exploração de seus esquemas figurais e gráficos.

A produção de material didático para a educação, seja básica ou superior, não tem sido profícua, ensejando uma metodologia de transmissão ou de posse de mecanismos operacionais técnicos, sem uma aprendizagem significativa. A concepção e desenvolvimento de materiais para instrumentalizar o processo de ensino e aprendizagem podem modelar novas metodologias, mais progressistas e de ativação colaborativa aluno/professor e aluno/aluno com intermediação das TICs por OA. 
Assim, ao produzir objetos de aprendizagem virtuais para rever e fundamentar conceitos, definições e proposições básicas para o entendimento dos conteúdos, presentes nas primeiras atividades de cada OA, construiu-se patamares para o estudante apropriar-se dos saberes técnicos com dimensão qualitativa e quantitativa, nas outras atividades.

Trata-se de trabalho com interdisciplinaridade, propiciando condições para uma aula de matemática contextualizada com a educação técnica profissional.

\section{Referências}

BORBA, Marcelo de Carvalho; PENTEADO, Miriam Godoy. Informática e Educação Matemática. 3.ed. 2.reimp. Belo Horizonte: Autêntica, 2007.

Decreto no 2.208 de 17 de abril de 1997. In: http://portal.mec.gov.br/seesp/arquivos/pdf/dec2208.pdf, acesso em 28/05/2017.

Decreto no 5.154 de 23 de julho de 2004. In: http://www.planalto.gov.br/ccivil_03/_ato2004-2006/2004/decreto/d5154.htm, acesso em 28/05/2017.

DUVAL, Raymond. Semiósis e pensamento humano - Registros semióticos e aprendizagens intelectuais. São Paulo: Livraria da Física, 2009.

KUENZER, Acácia Zeneida. Ensino Médio - construindo uma proposta para os que vivem do trabalho. São Paulo: Cortez, 2002.

MISKULIN, Rosana Giaretta Sguerra. As possibilidades didático-pedagógicas de ambientes computacionais na formação colaborativa de professores de matemática. In FIORENTINI, D. (Org.). Formação de professores de matemática: explorando novos caminhos com outros olhares. Campinas: Mercado das Letras, 2003. P. 217-248.

Página da Internet: https://phet.colorado.edu

PONTE, João Pedro da; OLIVEIRA, Hélia; VARANDAS, José Manuel. O contributo das tecnologias de informação e comunicação para o desenvolvimento do conhecimento e da identidade profissional. In: FIORENTINI, D. (Org). Formação de professores de Matemática. Campinas, SP: Mercado Letras, 2003.

STEWART, James. Cálculo. Volume 2. São Paulo: Pioneira Thompson Learning, 2003.

WILEY (II), David A. Learning Object Design and Sequencing Theory. 2000. 142f. Tese (Doutorado) - Brigham Young University.

ZABALA, Antoni. A prática educativa: como ensinar. Porto Alegre: Artmed, 1998. 
http://dx.doi.org/10.5965/2357724X06102018165

ZULLATO, Rúbia Barcelos Amaral. Professores de matemática que utilizam softwares de Geometria Dinâmica: suas características e perspectivas. Dissertação de Mestrado em Educação Matemática. Universidade Estadual Paulista, Rio Claro, 2002. 